\title{
An empirical study on the contribution of agricultural policy finance to agricultural economic growth in China
}

\author{
Tianzhen $\mathrm{Qi}^{1, \text { a }}$ Rui Sun ${ }^{2}$ \\ ${ }^{1}$ School of economics and management, Tianjin agricultural university, Tianjin 300384, China \\ ${ }^{2}$ School of economics and management, Tianjin College of Commerce, Tianjin 300000, China \\ a10984652@qq.com
}

Keywords: Agricultural policy financial ;institutions ;regression algorithm ;financing

\begin{abstract}
In recent years, China's rapid economic development, as a large agricultural country, the development of China's agricultural economy plays a vital role in economic development. Agricultural policy finance refers to the state governments to support their agricultural development, based on the basic strictly follow the national policy, the rational use of financing methods, and set up special preferential conditions for agriculture, for the funds to support and help the on agriculture. Our country has established a scientific and reasonable agricultural policy financial institutions, dedicated to providing financial assistance to agricultural production units, the main form of credit cooperatives, such as bank loans, can be used to assist the process of agricultural production, can also limit the price of agricultural products to protect the agricultural product market function. Based on agricultural policy finance on agricultural economic development contribution analysis and practical calculation, to prove the significance of agricultural policy finance in agricultural economic development, and on how to further play the role of.
\end{abstract}

\section{Introduction}

China is a large agricultural country, agriculture plays a very important role in the development of China's economic development, but the agricultural policy finance in accordance with national policy, through a variety of ways of financing to support agricultural development, which belongs to a kind of financial policy in agriculture financing, for the funds to support and help for agriculture. This reflects the national importance of agricultural development, and agricultural development has a great effect on the economic development of our country. Has a very important role in the agricultural policy finance for the development of agriculture, specifically responsible for the affairs of the organization is essential, such as China's Chinese Agricultural Bank, it is the specific institutions with the financial reform and the establishment of the service for the agricultural policy finance. Through countless examples of domestic and foreign development can prove that financial agricultural policy scientifically and reasonably can promote agricultural development, but the specific relationship and contribution way of agricultural policy finance and agricultural development also requires a detailed discussion, in order to seek a more appropriate financial plan and financing mode, to further promote the development of agriculture in China. [1]

\section{Agricultural policy finance}

History of agricultural policy finance. Agricultural policy finance refers to the state governments to support their agricultural development, based on the basic strictly follow the national policy, the rational use of financing methods, and set up special preferential conditions for agriculture, for financial support and help to the agriculture, it also reflects the national importance of agricultural development, agricultural development and the important the impact of China's economic development. Agricultural policy finance originated in Europe, in order to resist the invasion of foreign trade and vigorously develop its own agriculture, so its financial support and agricultural equipment. With the continuous development of handicrafts, agricultural production in the 
emergence of lending, and then the emergence of a special lending institutions in Italy. In the last century, the financial crisis in the United States in order to protect agriculture, to support agricultural production, introduced various policies and regulations, in the acquisition of agricultural production, sale, etc., to support a full range of agricultural [2], while the developed countries have to follow, is committed to supporting agriculture.

Development of agricultural policy finance. At present, with the development of economy, the policy of agrarian policy support to agriculture has been improved and perfected. Therefore, agricultural policy finance is the application of monetary support in agriculture. Agricultural policy finance is generally used in two aspects: on the one hand, it is to support and invest in the agricultural production process, improve the quality of agricultural products and improve the agricultural production structure. On the other hand is to limit the price of agricultural products and protection, such as the United States in the last century, the price of agricultural products. At present, China's rural food, edible oil and other products have a positive price, so as to avoid the loss of farmers in the acquisition of food and other matters. At present, the support to the agricultural economy is generally provided by the Agricultural Bank and the rural credit cooperative, and the burden of the agricultural development institution is reduced by the method of low interest rate or no interest repayment, which is helpful to the development of the agricultural economy. And bank loans and credit cooperatives loans provide a multi-faceted financial support for agricultural development, and has a certain size of the loan repayment process [3], showing its importance in agricultural progress.

\section{Empirical study on the contribution of agricultural policy finance to agricultural economic growth}

Analysis of agricultural economic growth factors. China's agricultural economic growth, including many essential factors, such as agricultural production planning, scientific rationality, efficient irrigation measures, training of agricultural professionals and agricultural integration scale etc.. Based on the analysis of the factors of agricultural economic growth, this paper selects several independent variables of capital, labor force, system and agricultural production technology. The analysis, in the agricultural economy, the contribution of the production of the increasing capital, capital including land agricultural production, the quality of the seedlings of crops is crucial for agricultural production; and the contribution of labor and institutional change has decreased, it is clear that the existing agricultural economic development more and more on modernization. The labor demand is gradually reduced, and more inclined to use advanced technology and equipment, and technical progress for the contribution of increased slightly, also illustrates this point, which also reflects the good trend of agricultural development in china.

Using linear regression model to analyze the agricultural policy finance. Now, we utilize professional statistical methods to analyze the various factors, and use the regression equation to calculate. First, the linear regression is a mathematical algorithm [4], to use the linear equation and the regression equation, when the independent variable is only one belonged to the simple model, the independent variables in the more than two belong to the complex model, and in this study, as an independent variable in the process of agricultural production has many factors, so it belongs to complex model. In the regression analysis, the relationship between the independent variable and dependent variable should be linear, and all the independent variables, the influence degree of the independent variables on the results can be determined according to the linear parameters. So it is very important to use a linear regression model to find out which factors are most important to the development of agricultural economy. The agricultural policy finance involves the circulation and the use of the fund, it is inevitable that there will be a certain risk, so the policy finance should be used to develop the agriculture. Agricultural production units are different, the scale of the industry, construction time and so on are not the same, we must take scientific methods and effective assessment policies and reasonable loan measures, provide help for the development of agriculture at the same time, to avoid unnecessary losses. 
Analyze the financial situation of agricultural policy finance. Agricultural economic development needs the support of capital, the source of funds is generally produced by the local government, agricultural production units such as joint investment, but larger funds for agricultural development, often lack of funds and other phenomena, so should try to attract more investment, to expand the capital, to meet more demand for units of agriculture. The financial support of pastoral policy finance is generally used in two aspects, on the one hand, it is to support and invest in the agricultural production process, improve the agricultural production structure. On the other hand, the price of agricultural products is limited and protected. In order to attract funds, we can establish a systematic way of shares, according to the development of an agricultural production unit, analysis of its future development trend, to attract interested companies to invest. Secondly, the use of social security, pension funds and other aspects of the direction of the source of funds to enrich the principal, so that the absorption of a large number of agricultural funds will be used in the development of the agrarian economy. The empirical data collected from the agrarian economy in recent years, the actual income of farmers, statistics are subject to some restrictions, but still has some reference value. The independent variable is the institution of agrarian policy finance, and the dependent variable is the real income data. The datum was analyzed by linear regression.

Regression calculation and analysis results. When the input variables can be obtained, with the strengthening of agricultural policy finance, farmers' income increase, rural economic development. In all of these ways of agricultural policy finance, the amount of bank loans is the biggest contributor, that agriculture in the process of development, requires a lot of financial support, and reasonable loan provided by the bank to solve the liquidity problem for agricultural production, to a certain extent, promoted the development of agriculture. But it was another reflection of rural credit cooperatives and other savings institutions, absorb a lot of rural capital, but doesn't have a lot of support for the development of rural economy, need to be improved and perfected, so that it has become the development of auxiliary agricultural institutions. In the increasingly rapid economic development today, should expand the scope of the use of agricultural policy finance, in the process of agricultural production and the price limit the application of extended to the processing of agricultural products, construction of agricultural products after processing, production, sales and other processes to provide financial support. In addition, the funds should be supported on the rural construction in all aspects of the process, we should improve the agricultural production environment, improve the living standards of farmers, the technology and equipment of agricultural production in the purchase, the more advanced and modern agricultural production.

Summary. Through the above analysis, we can see that the auxiliary function of many factors of rural economic growth, and especially with banks and credit cooperatives loans is an important condition, these funds support of great help in the development of agriculture, agricultural economic development the proportion has exceeded the labor conditions and mechanical conditions. With the development of agricultural economy in our country, the demand for labor is decreasing gradually, and the demand for advanced technology and equipment and production cost increases year by year. In addition, agricultural policy oriented financial institutions, the largest proportion of bank loans, financial support for the development of agricultural economy up to. And between bank loans and credit cooperatives loans, the role played by bank loans is much greater than the role of cooperatives. It also shows that the development of rural economy in our country is very dependent on the financial support for agriculture policy finance, more and more in the agricultural economic development plays an irreplaceable role in the future, to intensify the development of agricultural economy, must establish a scientific and reasonable financial support system, the agricultural policy finance existing more perfect, the the support to the development of agricultural economy to get more play, to further promote the development of agricultural economy in china.

\section{The rational use of agricultural policy finance in agricultural economic development}

Expand the scope of vigilance risk. On the one hand, the pastoral policy finance is used to support and invest in the agricultural production process. On the other hand, it is used to define and 
protect the price of agricultural products, such as the United States in the last century, the price of agricultural products have been limited to protect the interests of farmers and the normal operation of the agricultural market [5]. An agricultural policy financial institution should be in the lead of government planning, the agricultural production units, the national government and other relevant departments of investment were set up, there is a need for agricultural units to give loans to help, and to find effective guarantee. Second, the loan should be exempted from interest, the benefits of agrarian production and the state government to supplement. Should be based on the actual situation, the establishment of scientific and reasonable legal system, legal provisions constraints on related matters, and standardize the loan process, to ensure that every loan to make the best use, to avoid the occurrence of corruption. [6]

Improve the system, expand the scope of. Agricultural policy finance is a new mechanism for agricultural economic development to provide financial support, but the mechanism of leadership and management, personnel allocation, there are still some problems in the evaluation standard, we must carry on the improvement, in order to make its new vitality, provide strong support for agriculture economic development. First of all, reasonable planning competition system, agricultural policy finance funds must be used where it is most needed, so each unit of agricultural production should be carried out through reasonable competition, the scale of production, management, income level on the assessment, reasonable allocation of funds. On the other hand, financial institutions themselves should also be economical planning. In addition, financing of agricultural policy finance should follow the direction of the state, the majority of funds should be used to follow the national policy of agricultural production units, the remaining part of the appropriate small-scale agriculture. [7]

\section{Concluding remarks}

The development of the agricultural economy is good for China's economy has great influence, but the agricultural policy finance in accordance with national policy, through a variety of ways of financing to support agricultural development, plays a very important role in the economic development of our country, and responsible for the affairs of the organization is gradually perfected, and more indispensable. Through data statistics and regression algorithm, the paper analyzes the importance of agricultural policy financial institutions in the development of agricultural economy. With the development of agrarian economy in our country, the demand for labor is decreasing gradually, and the demand for advanced technology and equipment and production cost increases year by year. In addition, agricultural policy oriented financial institutions, the largest proportion of bank loans, financial support for the development of agricultural economy up to. Based on reasonable analysis, put forward how to better play the role of agricultural policy financial institutions, from the expansion of funding sources, effective risk prevention and follow government policy, the rational allocation and use of funds. I believe that through scientific and reasonable analysis, we can see that has a very important effect on the development of agricultural policy finance of China's modern agricultural economy, and the agricultural policy financial system continues to improve, can make better use of its support for agricultural production, to provide financial help to further promote the development of Agriculture in our country. Economy.

\section{References}

[1]Gao Y, Zheng J, Bu M. Rural-urban income gap and agricultural growth in China: An empirical study on the provincial panel data, 1978-2010[J]. China Agricultural Economic Review, 2014, 6(1):92-107.

[2]Tan H, Wang H, Chen L, et al. Empirical analysis on contribution share of safety investment to economic growth: A case study of Chinese mining industry[J]. Safety Science, 2012, 50(7):1472-1479. 
[3]Ke Y, Chen B, Du H, et al. The contribution of cultivated land occupation by construction to China’ s economic growth[J]. Journal of Geographical Sciences, 2011, 21(5):897-908.

[4]Peng Q H, Zeng L H. Empirical Study on the Contribution of Investment in Chinese Infrastructure to Its Economic Growth——Based on Data During 1953-2007[J]. Systems Engineering, 2009, 27(11):120-122.

[5]Gao Y, Zheng J, Bu M. Rural-urban income gap and agricultural growth in China[J]. China Agricultural Economic Review, 2014, 6(1):92-107.

[6]Chen H, Li G. Empirical study on effect of industrial structure change on regional economic growth of Beijing-Tianjin-Hebei Metropolitan Region[J]. Chinese Geographical Science, 2011, 21(6):708-714.

[7]Kumar R R, Stauvermann P J, Patel A. Exploring the link between research and economic growth: an empirical study of China and USA[J]. Quality \& Quantity, 2016, 50(3):1-19. 